\title{
Uncertainty Dimensions of Information Behaviour in a Group Based Problem Solving Context
}

\author{
Jette Hyldegård* \\ Royal School of Library and Information Science
}

\begin{abstract}
This paper presents a study of uncertainty dimensions of information behaviour in a group based problem solving context. After a presentation of the cognitive uncertainty dimension underlying Kuhlthau's ISP-model, uncertainty factors associated with personality, the work task situation and social settings are introduced. These different dimensions of uncertainty are explored in a longitudinal case study of three groups of LIS students (two groups with tree females and one group with three females and one male) while they were preparing a project assignment. It is explored to what extent group members' experiences of uncertainty differ from the individual information seeker in Kuhlthau's ISP-model, and how this experience may be related to personal, work task and social factors. A number of methods have been employed to collect data on each group member during the assignment process: a demographic survey, a personality test, 3 process surveys, 3 diaries and 3 interviews. It was found that group members' experiences of uncertainty did not correspond with the ISP-model in that other factors beyond the mere information searching process seemed to intermingle with the complex process of knowledge construction and meaning making. Personal factors and work task factors also caused manifestations of uncertainty, though under strong influence from social factors like familiarity with other group members and the group work process. It is concluded that the uncertainty concept is a multi-dimensional phenomenon, which should not be studied out of context. On the other hand, this complexity of the uncertainty concept also represents a methodological and practical challenge to the researcher as well as the practioner.
\end{abstract}

Keywords: information interaction; information architecture; group problem solving

\author{
*Contact: \\ Jette Hyldegård, Associate Professor, PhD \\ Royal School of Library and Information Science, Copenhagen, Denmark \\ E-mail: JH@db.dk
}




\section{Introduction}

Many conceptualisations and approaches to the study of uncertainty exist in information science research. Besides paradigm changes within the discipline itself variations also seem to exist according to differences in research focus and perspective - system versus human. In information retrieval (IR) research uncertainty has often been associated with probability theory and the reduction of noise in the transmission of information, which refers back to Shannon's theory of communication (Shannon \& Weaver, 1964). From a more user oriented perspective other IR-researchers (e.g. Belkin, Oddy \& Brooks, 1982) have been concerned with information need formulation and uncertainty reduction in response to a user's recognised gap or anomaly in his or her state of knowledge concerning some topic or situation. In information seeking research the focus has been on the information seeker's experiences of uncertainty and how research may help overcome the barriers to searching and knowledge construction that generally follow from identified experiences of uncertainty. According to Kuhlthau $(1991 ; 2004)$, for example, experiences of uncertainty are often identified at the initial stage of a complex problem solving process due to a gap in the information seeker's state of knowledge (cognitive uncertainty). This will change, however, as he or she gets information and constructs meaning. Manifestations of uncertainty have also been found in relation to the work task situation. Onwuegbuzie (1997), for example, found that anxiety among students correlated with aspects of the research process. Byström \& Järvelin (1995) also identified a correlation between perceived task complexity and experiences of uncertainty. Recently, personality traits have also been found to interfere with how the information seeker experience and react to uncertainty (e.g. Heinström, 2002).

Whereas previous research has demonstrated that a number of factors seem to influence the information seeker's experiences of uncertainty, studies of uncertainty have generally concentrated on the individualistic information seeker, though many of these also engage in group based problem solving and collaborative information behaviour (e.g. Case, 2007; Bruce et al., 2003; Fidel et al., 2000; Hyldegård, 2006a; 2009; Limberg, 1998; Prekop, 2002; Reddy \& Jansen, 2008; Sonnenwald \& Pierce, 2000). To further explore the complexity of the uncertainty concept this paper looks into the social dimension of uncertainty, but in addition to the cognitive, personal and work task dimension of uncertainty. More insight into the manifestations and implications of uncertainty, in this case in a group based setting, may better enable mediators such as teachers, supervisors and information specialists to help participants cope with uncertainty in a problem solving context for the benefit of learning and problem solving. According to Nahl (2007) uncertainty often manifests itself in negative feelings such as irritation, frustration, stress and even rage, which may affect peoples' perceived self-efficacy accordingly. On the other hand, being able to cope with uncertainty will provide people with a significant affective advantage indicated by higher optimism and lower uncertainty, hence, a smaller affective load.

This paper presents a study of uncertainty within three groups of LIS-students while they were preparing an assignment. The study is based on a larger study of group based information behaviour (Hyldegård, 2009).

The first part of the paper outlines the 'uncertainty principle' underlying Kuhlthau's ISPmodel and the different factors that have been found to trigger or influence the experience of uncertainty. The second part presents the research design of the study, that is, a description of the research questions, the participants, the work task and the employed data collection methods. Finally, in the last part of the paper the results of the study are presented and discussed, leading to the conclusion and implications for future research and practice. 


\section{Kuhlthau's 'Uncertainty Principle'}

During two decades of empirical research Kuhlthau has developed a conceptual framework and a model of the information seeking process (the ISP-model). As shown in figure 1 it consists of 6 stages, which show the individual information seeker's activities, thoughts and feelings over time while engaged in a work task such as a project assignment.

\begin{tabular}{|c|c|c|c|c|c|c|}
\hline Tasks & Initiation & Selection & Exploration & Formulation & Collection & Presentation \\
\hline $\begin{array}{l}\text { Feelings } \\
\text { (affective) }\end{array}$ & Uncertainty & Optimism & $\begin{array}{l}\text { Confusion/ } \\
\text { frustration/doubt }\end{array}$ & Clarity & $\begin{array}{l}\text { Sense of } \\
\text { direction/ } \\
\text { confidence }\end{array}$ & $\begin{array}{l}\text { Satisfaction or } \\
\text { disappointment }\end{array}$ \\
\hline $\begin{array}{l}\text { Thoughts } \\
\text { (cognitive) }\end{array}$ & vague .............. & 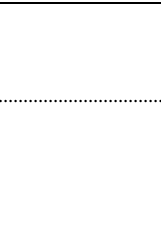 & 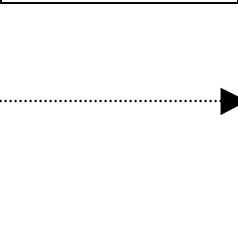 & focused & eased interest & 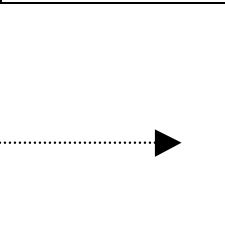 \\
\hline $\begin{array}{l}\text { Actions } \\
\text { (physical) }\end{array}$ & $\begin{array}{l}\text { seeking relev } \\
\text { documenting }\end{array}$ & information & xploring ................................. & 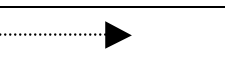 & seeking per & tinent information, \\
\hline
\end{tabular}

Figure 1. The model of the Information Search Process (Kuhlthau, 2004, p. 82).

Depending on the specific stage of the process, activities, thoughts and feelings will change. The information seeker often feels uncertain at the initial stage deriving from a lack of knowledge or a vague understanding to solve the problem at hand. This will change as he/she gets knowledge, constructs meaning and formulates a focus. The finding of a focus generally implies that negative feelings start to decrease whereas positive feelings start to increase.

According to Kuhlthau (2004) uncertainty that is caused by a lack of understanding or a knowledge gap is a natural experience within the process of information seeking and meaning making, hence a premise underlying the information seeking process. It is associated positively with the knowledge construction process, reflecting the beginning of learning and creativity. The same positive aspect of uncertainty in information seeking was found in a recent longitudinal case study of uncertainty within the creative process of scholarly research (Anderson, 2006). Anderson found that positive forms of uncertainty often, though not exclusively, were associated with the informants' explorations within the wider research tasks in which they were engaged. In addition, positive and negative forms of uncertainty tended to interact dynamically. According to Kuhlthau (2004), these moments of perceived uncertainty during an information seeking process may also be seen as potential 'zones of intervention' (Kuhlthau, 2004). A zone of intervention is that area in which an information seeker can do with advice and assistance from a human or digital mediator what he or she cannot do alone or can do only with great difficulty in order to accomplish his/her task (Kuhlthau, 2004).

Kuhlthau's approach to uncertainty is referred to as the 'uncertainty principle' and reflects the cognitive dimension of uncertainty in this paper. Other dimensions of uncertainty in information behaviour research exist, which are presented below. 


\section{Personality Dimensions of Uncertainty}

Experiences of uncertainty and information behaviour have also been found to be associated with personality traits. According to Huber et al (1992), Sorrentino, Hodson and Huber (2001) and Sorrentino and Roney (2000) people may be characterized on a continuum from certaintyoriented (CO) to uncertainty-oriented (UO). For UOs, the preferred method of handling uncertainty is to seek out information and engage in activities that will directly resolve uncertainty and attain clarity. CO's on the other hand, develop a self-regulatory style that circumvents uncertainty confrontation. Such persons will generally undertake activities that maintain clarity, hence do not involve uncertainty. If, however, they are confronted with uncertainty situations, they will rely on others and/or heuristic devices over more direct methods of resolving uncertainty.

The same pattern was identified by Heinström (2002) in a large scale quantitative study exploring the relation between personality traits and information seeking behaviour. She found among others that informants with a low level of 'neuroticism' ${ }^{1}$ had a constructive and positive attitude towards information and appreciated a large recall. The more secure, the more actively they searched for information. In contrast, informants with a high level of 'neuroticism' had difficulties in coping with unpredictability, disorder and ambiguity in search systems.

Despite the demonstrated influence from personality traits on information behaviour these traits are, however, only dispositions to behaviour rather than absolute and predetermined characteristics of human behaviour (Humpheys \& Revelle, 1984). When exploring personality traits the result always needs to be analysed in combination with the specific situation and context framing the individual's behaviour, e.g. the work task situation.

\section{Work Task Dimensions of Uncertainty}

Uncertainty may also derive from the context, e.g. the very work task and the work task situation framing the information seeking process. Onwuegbuzie (1997), for example, investigated how various forms of anxiety were related to the research process in a study with 81 graduate students. The results showed that anxiety correlated with aspects of the work task as well as with personality. Kracker (2002) and Kracker and Wang (2002) investigated the 'research model' implied in the ISP-model and the importance of students' awareness of this model. Ninety undergraduate students participated in the study. Besides similarities in affective experiences between this study and the ISP-model and the positive impact from educational intervention on perceived anxiety, anxiety associated with the research process was also found. It was, for example, identified in relation to the start of research, collection of information, writing and time management. It was concluded that uncertainty and anxiety must lie within the process itself, not within the individual - in contrast to Heinström (2002) and Onwuegbuzie (1997). The perceived complexity of a work task has also been found to influence the individual's experience of uncertainty and his or her information behaviour (e.g. Byström, 1999; Byström \& Hansen, 2005; Byström \& Järvelin, 1995). In a longitudinal study at a city secretarial office in Finland (Byström \& Järvelin, 1995) it was found that as task complexity increased, so did the complexity of the information needed, the needs for domain and problem solving information, the number of sources used as well as the share of general-purpose sources. Further, dead ends in complex tasks often led to many information seeking actions with anxiety. Differences between simple and complex tasks lead to the hypothesis that the affective dimension is often not as marked in simple tasks as in complex tasks. In complex tasks, on the other hand, lack of motivation and anxiety seemed to have an overall effect on performance. The perceived level of search task and work task knowledge may also influence on the individual's

\footnotetext{
${ }^{1}$ Neuroticism is one of the five personality factors in the widespread personality test instrument NEO-PI-R developed by Costa and McCrae (1997) that generally is associated with manifestations of uncertainty.
} 
perception of task complexity and uncertainty (Ingwersen \& Järvelin, 2005). Experiences of uncertainty have also been found to relate to the outcome of the work task process. In a case study by Cheuk Wai-Yi (1998) eight knowledge workers were followed while preparing an audit assignment. In contrast to the ISP-model it was found that the participants started their work with confidence and ended up with stress and frustration when their ideas did not correspond with the information gathered, which implied a delay in their work. Moreover, when finalising their ideas they felt anxious about how their work would be judged and valued and if they would add value to the company.

\section{Social Dimensions of Uncertainty}

This section focuses on the social dimension of uncertainty. It is primarily based on findings from social psychology regarding interpersonal relations and group settings.

According to Berger and Calabrese (1975) uncertainty is one of the most universal individual difference characteristics that can influence the social mind. The entire goal of interpersonal relations is to reduce uncertainty about the message conveyed and the relations between the communicators. Further, uncertainty reduction is a major force behind the need for perceptions of group entitativity ${ }^{2}$ and feelings of group belongingness (Brewer \& Harasty, 1996). In addition, the way people deal with uncertainty in an interpersonal context also have a major impact on many kinds of strategic social behaviours, e.g. reflected in group decisions and intergroup conflicts (Sorrentino, Hodson \& Huber, 2001).

New groups idealistically develop through four stages, also known as the 'forming'-, 'storming'-, 'norming'- and 'performing' stages (Tuckman, 1965). At the 'forming'-stage the group members first come together. They are generally polite to each other at this stage and conflicts are seldom seen. At the 'storming'-stage, in turn, fractions are formed, personalities clash and conflicts are dominating due to the transition from being an individual person to become a group member. At the 'norming'-stage the group starts to recognize the merits of working together, thus, sub-sides the in-fights. From the new spirit of co-operation each group member begins to feel more secure and express his/her thoughts that now are discussed more openly. In addition, work methods are established and recognized by the group as a whole. Finally, at the 'performing'-stage the group has settled on a system of norms, which allow for an open and frank exchange of thoughts as well as a high degree of support by the group. Conflicts may, however, still arise at this stage and momentary return the group to the 'storming'-stage. In addition, groups may not always succeed in establishing a strong group identity, implying a 'wemode'orientation towards the group's interests, negotiated goals, values, opinions and norms that bind the group together (Tuomela \& Tuomela, 2005). In some groups a strong 'I-mode'orientation exist, which mean an orientation towards own interests. This was for example seen in Limberg's (1998) study of 25 high school students and their group based information seeking behaviour while they were preparing an assignment ${ }^{3}$. She identified two categories of group approaches in terms of the groups' approach to group work and information seeking. The 'holistic' approach was characterized by groups acknowledging the value of group work and considering group work as a collective task towards a shared goal, implying various group activities to succeed. They considered the establishment of a shared knowledge base as very important, which also was demonstrated in their information behaviour. In contrast, the 'atomistic' approach was characterised by groups of individuals, who had organised the group work according to specific parts of the assignment, which had been delegated to each group

\footnotetext{
${ }^{2}$ Entitativity is defined here as the degree of having the nature of an entity, of having real existence, hence a measure expressing the perceived degree of 'group entity' (Castano, Yzerbyt, Paladino, \& Sacchi, 2002)

${ }^{3}$ The social dimension of information seeking and problem solving was, however, not the focus of Limberg's study.
} 
member. They were generally lacking a perception of the 'whole', meaning the collective product to be submitted. The work was divided between the group members and they did not meet outside the school schedule, hence worked more on an individually basis. This was also reflected in their approach to information behaviour, since they did not effectively communicate information in the group, nor aimed at building up a shared knowledge base.

The previous sections have presented various conceptualisations and manifestations of uncertainty that form the theoretical foundation of the uncertainty study presented and discussed below.

\section{The uncertainty study}

The uncertainty study was carried out in 2008 , and it is based on the data from a larger research project of group members information behaviour during a project assignment process. The aim of the larger case study was to explore to what extent group members' information behaviour compared to the individual modelled in Kuhlthau's $(1991 ; 2004)$ ISP-model when social, contextual (work task) and personal (personality) factors were taken into account. More specifically, the aim was to explore the influence from these factors (in addition to the mere information seeking process) on group members' actions as well as cognitive and affective experiences during a complex problem solving process ${ }^{4}$. A number of data were collected by means of a demographic questionnaire, a personality test, process surveys, diaries and interviews. Data were collected at start, midpoint and end of the assignment process to track changes in behaviour over time. With regard to the present uncertainty study relevant data have been extracted from the larger pool of data and analysed with a new set of research questions in mind that focus specifically on the uncertainty dimension of group based information behaviour. In line with Nahl (2007) 'uncertainty' in this study also implies manifestations of uncertainty, such as anxiety, doubt, frustration and stress ${ }^{5}$.

The research design and its implications for the uncertainty study will be described below. For a more detailed presentation of the research design and employed methods of the larger study, see Hyldegård (2009).

\section{Research Questions}

The aim of the study was to further explore the uncertainty dimension of information behaviour when focusing on group members, e.g. in which way their experiences of uncertainty tended to differ from the individual information seeker in the ISP-model and why ${ }^{6}$. The following two research questions were formulated:

1. How do group members' experiences of uncertainty correspond with the individual's affective behaviour in the ISP-model?

2. How is the experience of uncertainty related to:

- personal factors?

- work task factors?

- social factors?

\footnotetext{
${ }^{4}$ The larger research project on group members' information behaviour is a follow up on Hyldegård (2006a) and is further presented in Hyldegård (2006b) as well as in Hyldegård (2009).

${ }^{5}$ Though defined here by negative feelings, uncertainty may also result in constructive forms of behaviour.

${ }^{6}$ Information behaviour is here defined as "...those activities a person may engage in when identifying his or her ownneeds for information, searching such information in any way and using or transferring that information" (Wilson, 1999, p. 249).
} 


\section{Participants}

The participants were ten Danish graduate students in library and information science studying at their fifth term. At this level the curriculum is dedicated to problem based project work and group work accordingly. The students ranged from 23 to 48 years of age, nine were females and one was male. They voluntarily formed two 3-person groups and one 4-person group (the male was in the last group). Participants were experienced information seekers and had previous experience with group based and individual based project assignments.

\section{Work Task}

The work task, the project assignment, was a mandatory part that lasted fourteen weeks, from week 412004 to week 01 2005. During this period the students had to formulate a problem within a specific project topic, explore the topic and find a focus, find and digest relevant literature, collect and analyse data, devise a structure for presenting their argument and finally write a project report. The project report approximated 30-40 pages for groups of students. The work task is primarily addressed at the descriptive level in this paper, but when referring to the work task process it refers to the three stages introduced by Vakkari (2001), which correspond with the ISP-model: the pre-focus stage (initiation, selection and exploration), the focus formulation stage (formulation) and post-focus stage (collection and presentation).

\section{Data Collection}

Figure 2 shows the methodological framework of the larger research project, which this study is based on.

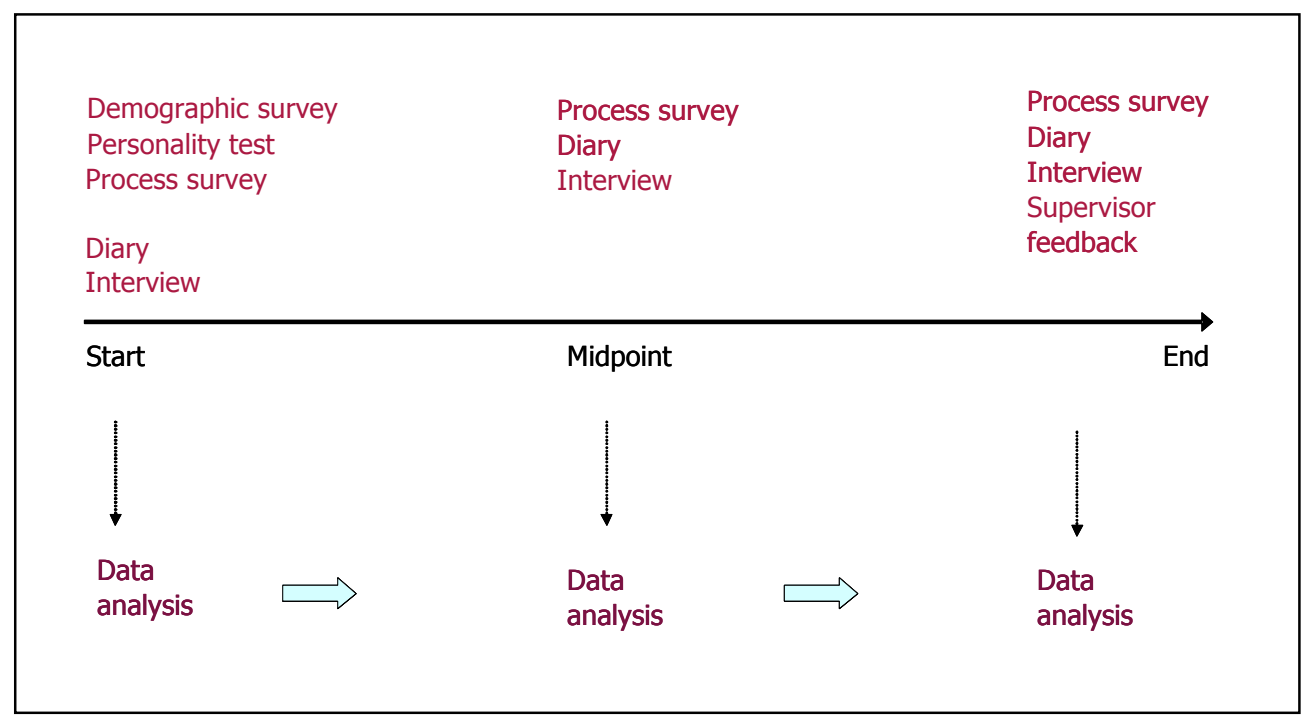

Figure 2. Methodological framework of the larger research project. It shows the various methods emplyed at start, midtpoint and end of the project assignment process and how data analysis was integrated into the overall data collection process.

Three type of methods were selected for data collection: questionnaires (a demographic survey, a personality test and process surveys), diaries and interviews ${ }^{7}$. The data were collected at three points in the assignment process: start, midpoint and end. Further, to facilitate the data

\footnotetext{
${ }^{7}$ The use of various methods - triangulation - is often seen in case studies as a way to provide an in-depth exploration of a complex phenomenon as well as to help validate important findings in the data.
} 
collection process a ring binder was handed out to each participant containing all relevant material to be used in the study. All participants signed a consent of participation.

The demographic survey consisted of twenty-three questions and statements with the aim of collecting profile information of each participant (gender, age, prior experience in terms of group work, the subject of interest, IT and information seeking).

To describe and compare each group member's personality traits at a more detailed level the personality test instrument NEO-PI-R was employed (Costa \& McCrae, 1992; 1997). The NEOPI-R measures differences in cognitive, affective and social behaviour according to five general personality factors: neuroticism, extraversion, openness to experience, agreeableness and conscientiousness. Each of these is a summarization of six facets. 'Neuroticism', which is relevant in this context, is a summarization of anxiety, temper, pessimism, social fear, impulsiveness and nervousness. Each of the five factors and their associated 6 facets is measured through 48 statements, implying that all 30 facets are measured through 240 statements. Each statement is answered on a five point scale, ranging from 'strongly disagree' to 'strongly agree'. The result of the 240 statements is then calculated into T-scores for every factor and facet ranging from 'very low' to 'very high' according to the underlying norm groups of the test instrument. All participants were given a short introduction to the personality test and its use at start before they were asked to reply to the 240 statements in the questionnaire.

To elicit behaviour over time associated with the project assignment, information seeking and group work a printed process survey was filled out by participants and handed in at three selected points (dates) in the process ${ }^{8}$. The three process surveys were identical in order to observe changes over time. To observe progress in focus formulation during time, for example, the first question in each process survey asked for a short topic description and a title of the assignment 'right now'. In the same way, each process survey asked for group members' judgement of information 'at the moment' in order to observe if relevance judgements changed from 'relevant' at start to 'pertinent' at the end of information seeking. With relevance to the present uncertainty study affective aspects associated with the project assignment were addressed in the process survey by asking each participant to state his or her emotional experiences with a number from 0 (not recognized) to 5 (high) in relation to 6 positive feelings (confident, satisfied, optimistic, relieved, motivated and clarity (a sense of direction) and 7 negative feelings (confused, doubt, stressed, frustrated, uncertain, worried/cautious). To address the affective aspects associated specifically with information seeking, each participant should also indicate his or her experience of information seeking according to four pairs of positive and negative feelings on a scale from 1 (positive) to 5 (negative). The positive feelings and their corresponding negative feelings were: easy/difficult, relaxing/stressing, simple/complex and satisfying/frustration. If other pairs of positive and negative feelings had been experienced, the participants were allowed to note these in the survey and mark the value accordingly.

Each process survey was followed by a one week diary period (7 days) to collect data on a daily basis on each group member's activities and experiences related to the work task, information seeking and group work The printed diary should also guide the interviews with the participants afterwards; both when deciding which issues to address in the interviews and during the interviews when referring to specific incidents. Further, the aim of the diary was to act as a surrogate for direct observation. The participants were instructed to record on a daily basis and in their own words any assignment-related activity. The activities should be described chronologically and at best immediately after the activity had taken place. In the final part of the diary, the participants should indicate their recognition and experience of each of the listed

\footnotetext{
${ }^{8}$ The process surveys were handed in at three selected dates: 1) 22 October 2004, 2) 19 November 2004 and 3 ) 17 December 2004.
} 
positive and negative feelings with a number from 0 (not recognized) to 5 (highly recognized) 9 . Recognized feelings not represented on the list should be noted with a value under 'Other'. The affective part of the diary should be filled out daily, even if no assignment-related activities had taken place. To clarify and qualify the use and outcome of the diary was pilot tested for two days prior to the official start of the larger research project.

Each diary period was followed by an interview with each group member, that lasted for 45 minutes. By interviewing the participants individually it became possible to explore whether and how group members differed in their perception and experience of identical situations (personal dimension); whether and how their work task and information related activities were individually or collaboratively based and, further, how perceptions and experiences evolved over time. A semi-structured guide was made for each of the three interview sessions, which addressed different aspects related to the work task, information seeking and group work in accordance with the specific point in the process. The form of the interview was guided by the micro-moment time-line technique derived from the Sense-Making approach (Dervin, 1983). All 30 interviews were recorded.

\section{Data Analysis}

The demographic survey generated categorical data and profile information of each group member. With regard to the personality test the calculation of test data resulted in various Tscores on factors and facets which have been plotted into a scoring scheme for each group member ranging from 'very low' (-34) to 'very high' (66- $)^{10}$. Concerning the uncertainty study the analysis will concentrate on scorings related to the factor 'neuroticism'. The influence from neuroticism, however, needs to be interpreted in combination with other personality traits. The factors, facets and T-score values of the test instrument are presented in table 1.

The data from the 30 process surveys were plotted into MS Excel, and matrices and graphical diagrams were generated to show relevant process data across group members and across time. The 30 diaries generated descriptive data on 'activities' and comments as well as data on 'feelings' perceived by the participants during the project assignment. These affective data were registered and analysed in MS Excel. The rest of the diaries were coded in the qualitative data analytical program ATLAS.ti. The 30 interviews were transcribed and coded in ATLAS.ti as well. For the purpose of this study relevant data have been extracted from the larger pool of data,, e.g. by codes assigned by the help of Atlas.ti and analysed in accordance with the two research questions on uncertainty.

\footnotetext{
${ }^{9}$ The feelings were similar to the feelings related to the work task in the process survey

${ }^{10} \mathrm{~A}$ T-score is a standardised value with a mean value of 50 . It is based on the $t$ - distribution and the scores range from 0 to 100. The standard score indicates the distance to the mean. It allows comparison of observations from different normal distributions.
} 


\begin{tabular}{|c|c|c|c|c|c|c|}
\hline & & \multicolumn{5}{|c|}{ T-scores } \\
\hline & & Very low & Low & Medium & High & Very high \\
\hline Factors & Facets & $<34$ & $35-44$ & $45-55$ & $56-65$ & $66<$ \\
\hline $\begin{array}{l}\text { Neuroticis } \\
\mathrm{m}\end{array}$ & $\begin{array}{l}\text { Anxiety, Temper, } \\
\text { Pessimism, Social Fear, } \\
\text { Impulsiveness, } \\
\text { Nervousness } \\
\end{array}$ & $\begin{array}{l}\text { Emotional stability: } \\
\text { calm, confident, } \\
\text { stress resistent }\end{array}$ & \multicolumn{3}{|c|}{$\begin{array}{l}\text { Calm, can handle stress, } \\
\text { sometimes he/she feels guilt, } \\
\text { anger and worry }\end{array}$} & $\begin{array}{l}\text { Anxiety: tendency to } \\
\text { worrying. Opset in stressing } \\
\text { situations }\end{array}$ \\
\hline $\begin{array}{l}\text { Extraver } \\
\text { sion }\end{array}$ & $\begin{array}{l}\text { Warmth, Gregariousness, } \\
\text { Assertiveness, Activity, } \\
\text { Excitement-Seeking, } \\
\text { Positive Emotions }\end{array}$ & $\begin{array}{l}\text { Introversion: } \\
\text { introvert, reserved, } \\
\text { serious. Prefers to } \\
\text { work individually }\end{array}$ & \multicolumn{3}{|c|}{$\begin{array}{l}\text { Moderate level of activity - both } \\
\text { individually and in groups }\end{array}$} & $\begin{array}{l}\text { Extraversion: extrovert, } \\
\text { open, higl level of activity, } \\
\text { likes to collaborate, does } \\
\text { not mind taking a leading } \\
\text { role }\end{array}$ \\
\hline $\begin{array}{l}\text { Openness } \\
\text { to } \\
\text { experience }\end{array}$ & $\begin{array}{l}\text { Fantasy, Aesthetics, } \\
\text { Feelings, Actions, Ideas, } \\
\text { Values }\end{array}$ & $\begin{array}{l}\text { Concrete thinking: } \\
\text { down to earth, } \\
\text { practical, } \\
\text { conventional, } \\
\text { technical approach } \\
\text { to problem solving }\end{array}$ & \multicolumn{3}{|c|}{$\begin{array}{l}\text { Practical approach, but also open, } \\
\text { a balance between old and new }\end{array}$} & $\begin{array}{l}\text { Openness: open towards } \\
\text { new experiences, creative, } \\
\text { broad filed of interests, } \\
\text { conceptual approach to } \\
\text { problem solving }\end{array}$ \\
\hline $\begin{array}{l}\text { Agreeable- } \\
\text { ness }\end{array}$ & $\begin{array}{l}\text { Trust, Straightforwardness, } \\
\text { Altruism, Compliance, } \\
\text { Modesty, Tender- } \\
\text { Mindedness }\end{array}$ & $\begin{array}{l}\text { Unfriendly: } \\
\text { opstinate, sceptical, } \\
\text { proud, impersonal, } \\
\text { competitive }\end{array}$ & \multicolumn{3}{|c|}{$\begin{array}{l}\text { Generally warm and friendly, } \\
\text { sometimes competitive and } \\
\text { opstinate }\end{array}$} & $\begin{array}{l}\text { Friendly: empathy, kind, } \\
\text { collaborative }\end{array}$ \\
\hline $\begin{array}{l}\text { Conscien- } \\
\text { tiousness }\end{array}$ & $\begin{array}{l}\text { Competence, Order, } \\
\text { Dutifulness, Achievement- } \\
\text { Striving, Self-Discipline, , } \\
\text { Deliberation }\end{array}$ & $\begin{array}{l}\text { Unconcerned: } \\
\text { spontaneous, laid } \\
\text { back, does not like } \\
\text { details, but flexible } \\
\text { plans and } \\
\text { procedures }\end{array}$ & \multicolumn{3}{|c|}{$\begin{array}{l}\text { Trustworthy and relative well } \\
\text { organised, clear goals, but may put } \\
\text { aside things in specific situations }\end{array}$} & $\begin{array}{l}\text { Conscientious-ness: } \\
\text { conscientious and } \\
\text { trustworthy, efficient, } \\
\text { concrete details, preferes } \\
\text { routines and predictive } \\
\text { procedures, strong feeling } \\
\text { of responsibility }\end{array}$ \\
\hline
\end{tabular}

Table 1. Factors, facets and T-score values of NEO-PI-R. A T-score at 34 and below is considered as 'very low', a T-score between 35 and 44 is considered as 'low', a T-score between 45 and 55 is considered as 'medium' and averagely, a T-score between 56 and 65 is considered 'high' and, finally, a T-score at 66 and above is considered 'very high'.

\section{Results}

The results of the uncertainty study are presented in four subsections that lead to the discussion of the two research questions. The subsections are: 1) group members' personality traits 2) affective experiences and the work task process, 3) affective experiences and the group work process and 4) affective experiences and the information seeking process.

Groups are referred to as group $\mathrm{A}, \mathrm{B}$ and $\mathrm{C}$ and group members are accordingly referred to as $\mathrm{A} 1, \mathrm{~A} 2, \mathrm{~A} 3 ; \mathrm{B} 1, \mathrm{~B} 2, \mathrm{~B} 3 ; \mathrm{C} 1, \mathrm{C} 2, \mathrm{C} 3, \mathrm{C} 4$.

\section{Group Members' Personality Traits}

To ease the identification of group members' personality traits and the comparison of the NEOPI-R test result across groups, the group members have been distributed according to their Tscores on both factors and facets as shown in table 2 . 


\begin{tabular}{|c|c|c|c|c|c|}
\hline & Very low & Low & Medium & High & Very high \\
\hline T-scores & -34 & $35-44$ & $45-55$ & $56-65$ & $66-$ \\
\hline Neuroticism (N) & & B3 & $\mathrm{A} 1, \mathrm{C} 2, \mathrm{C} 4$ & $\mathrm{~A} 2, \mathrm{~A} 3, \mathrm{~B} 1, \mathrm{~B} 2, \mathrm{C} 1, \mathrm{C} 3$ & \\
\hline Anxiety & & $\mathrm{B} 3, \mathrm{C} 4$ & $\mathrm{~A} 2, \mathrm{~B} 1, \mathrm{C} 1, \mathrm{C} 2, \mathrm{C} 3$ & $\mathrm{~A} 1, \mathrm{~A} 3, \mathrm{~B} 2$ & \\
\hline Temper & B3 & & $\mathrm{A} 1, \mathrm{~B} 1, \mathrm{C} 2, \mathrm{C} 3, \mathrm{C} 4$ & $\mathrm{~A} 2, \mathrm{~A} 3, \mathrm{~B} 2$ & $\mathrm{C} 1$ \\
\hline Pessimism & B3 & $\mathrm{A} 1, \mathrm{C} 2$ & $\mathrm{C} 3, \mathrm{C} 4$ & $\mathrm{~A} 2, \mathrm{~A} 3, \mathrm{~B} 1, \mathrm{C} 1$, & B2 \\
\hline Social fear & & $\mathrm{A} 1, \mathrm{C} 2$ & $\mathrm{~A} 3, \mathrm{~B} 3, \mathrm{C} 3, \mathrm{C} 4$ & $\mathrm{~A} 2, \mathrm{~B} 2, \mathrm{C} 1$ & B1 \\
\hline Impulsiveness & & & $\mathrm{A} 1, \mathrm{~A} 3, \mathrm{~B} 2, \mathrm{~B} 3$ & $\mathrm{~A} 2, \mathrm{~B} 1, \mathrm{C} 1, \mathrm{C} 4$ & $\mathrm{C} 2, \mathrm{C} 3$ \\
\hline Nervous & & C4 & $\mathrm{A} 1, \mathrm{~B} 3, \mathrm{C} 1, \mathrm{C} 2, \mathrm{C} 3$ & $\mathrm{~A} 2, \mathrm{~B} 1$ & $A 3, B 2$ \\
\hline Extraversion $(E)$ & & & $\mathrm{A} 1, \mathrm{~A} 2, \mathrm{~A} 3, \mathrm{~B} 1, \mathrm{C} 1, \mathrm{C} 2$ & B2, B3, C3, C4 & \\
\hline Warmth & & $\mathrm{C} 1$ & $\mathrm{~A} 1, \mathrm{~A} 2, \mathrm{~A} 3, \mathrm{C} 2, \mathrm{C} 3$ & $\mathrm{~B} 1, \mathrm{~B} 2, \mathrm{C} 4$ & B3 \\
\hline Gregariousness & & $\mathrm{A} 1, \mathrm{~A} 2, \mathrm{C} 1$ & $\mathrm{~A} 3, \mathrm{~B} 1, \mathrm{~B} 3, \mathrm{C} 2$ & $\mathrm{~B} 2, \mathrm{C} 3, \mathrm{C} 4$ & \\
\hline Assertiveness & & & $\mathrm{A} 1, \mathrm{~A} 2, \mathrm{~A} 3, \mathrm{~B} 1, \mathrm{C} 2$ & $\mathrm{~B} 2, \mathrm{C} 3, \mathrm{C} 4$ & $\mathrm{C} 1$ \\
\hline Activity & & $\mathrm{A} 2, \mathrm{~A} 3, \mathrm{~B} 1, \mathrm{~B} 2, \mathrm{C} 1, \mathrm{C} 2$ & $\mathrm{~A} 1, \mathrm{~B} 2$ & $\mathrm{C} 3, \mathrm{C} 4$ & \\
\hline Excitement seeking & & $\mathrm{A} 1$ & $\mathrm{C} 1, \mathrm{C} 4$ & $\mathrm{~A} 2, \mathrm{~A} 3, \mathrm{~B} 1, \mathrm{~B} 2, \mathrm{~B} 3, \mathrm{C} 2, \mathrm{C} 3$ & \\
\hline Positive emotions & & & $\mathrm{A} 2, \mathrm{~A} 3, \mathrm{~B} 1, \mathrm{C} 1$ & $\mathrm{~A} 1, \mathrm{~B} 2, \mathrm{C} 2, \mathrm{C} 3, \mathrm{C} 4$ & B3 \\
\hline $\begin{array}{l}\text { Openness to } \\
\text { experience (0) }\end{array}$ & & & A1 & $\mathrm{A} 2, \mathrm{~A} 3, \mathrm{~B} 1, \mathrm{~B} 2, \mathrm{~B} 3, \mathrm{C} 3, \mathrm{C} 4$ & $\mathrm{C} 1, \mathrm{C2}$ \\
\hline Fantasy & & & $\mathrm{A} 1$ & $\mathrm{~A} 2, \mathrm{~B} 1, \mathrm{~B} 2, \mathrm{C} 3, \mathrm{C} 4$ & $\begin{array}{l}\text { A3, B3, C1, } \\
\text { C2 }\end{array}$ \\
\hline Aesthetics & & $\mathrm{A} 1, \mathrm{C} 3$ & $\mathrm{~A} 2, \mathrm{~B} 2$ & $\mathrm{~A} 3, \mathrm{~B} 1, \mathrm{C} 1, \mathrm{C} 4$ & $\mathrm{~B} 3, \mathrm{C} 2$ \\
\hline Feelings & & B1 & $\mathrm{C} 2, \mathrm{C} 4$ & $\mathrm{~A} 1, \mathrm{~A} 2, \mathrm{~A} 3, \mathrm{C} 1$ & $\mathrm{~B} 2, \mathrm{~B} 3, \mathrm{C} 3$ \\
\hline Actions & & $\mathrm{A} 1$ & $\mathrm{~A} 2, \mathrm{~A} 3, \mathrm{~B} 2, \mathrm{~B} 3, \mathrm{C} 1$ & $\mathrm{~B} 1, \mathrm{C} 2, \mathrm{C} 3, \mathrm{C} 4$ & \\
\hline Ideas & & C3 & $\mathrm{B} 2, \mathrm{~B} 3, \mathrm{C} 4$ & $\mathrm{~A} 2, \mathrm{~A} 3, \mathrm{~B} 1, \mathrm{C} 2$ & $\mathrm{~A} 1, \mathrm{C} 1$ \\
\hline Values & & & $\mathrm{A} 3, \mathrm{~B} 3$ & $\mathrm{~A} 1, \mathrm{~A} 2, \mathrm{~B} 2, \mathrm{C} 1, \mathrm{C} 2, \mathrm{C} 4$ & $\mathrm{~B} 1, \mathrm{C} 3$ \\
\hline Agreeableness (A) & A3 & $A 1, A 2, B 2, C 3$ & $\mathrm{C} 1, \mathrm{C} 4$ & $\mathrm{~B} 1, \mathrm{C} 2$ & B3 \\
\hline Trust & & $\mathrm{A} 3, \mathrm{C} 1, \mathrm{C} 3$ & $\mathrm{~A} 1, \mathrm{~A} 2, \mathrm{~B} 1, \mathrm{~B} 2$ & $\mathrm{C} 2, \mathrm{C} 4$ & B3 \\
\hline Straightforwardness & $\mathrm{A} 2, \mathrm{~A} 3, \mathrm{~B} 2$ & $\mathrm{~A} 1, \mathrm{C} 3$ & $\mathrm{C} 1, \mathrm{C} 4$ & $\mathrm{~B} 1, \mathrm{C} 2$ & B3 \\
\hline Altruism & & $A 1, A 3, B 2, C 3$ & $\mathrm{~A} 2, \mathrm{~B} 1, \mathrm{C} 1$ & $\mathrm{C} 2, \mathrm{C} 4$ & B3 \\
\hline Compliance & $\mathrm{C} 3$ & $\mathrm{~A} 3, \mathrm{~B} 2, \mathrm{C} 4$ & $\mathrm{~A} 1, \mathrm{~A} 2, \mathrm{C} 1, \mathrm{C} 2$ & B1, B3 & \\
\hline Modesty & $\mathrm{A} 3$ & $\mathrm{~A} 1, \mathrm{C} 3$ & $\mathrm{~A} 2, \mathrm{C} 1, \mathrm{C} 2, \mathrm{C} 4$ & & \\
\hline Tender mindedness & & & $\mathrm{A} 1, \mathrm{~A} 2, \mathrm{~A} 3, \mathrm{~B} 1, \mathrm{~B} 2, \mathrm{C} 1, \mathrm{C} 2, \mathrm{C} 3$ & $\mathrm{~B} 3, \mathrm{C} 4$ & \\
\hline Conscientiousness (C) & B1 & $\mathrm{C} 4$ & $\mathrm{~A} 1, \mathrm{~A} 2, \mathrm{~A} 3, \mathrm{~B} 2, \mathrm{C} 1, \mathrm{C} 2, \mathrm{C} 3$ & & B3 \\
\hline Competence & & B1 & $\mathrm{A} 2, \mathrm{~A} 3, \mathrm{C} 1, \mathrm{C} 4$ & $\mathrm{~A} 1, \mathrm{~B} 2, \mathrm{~B} 3, \mathrm{C} 2, \mathrm{C} 3$ & \\
\hline Order & $\mathrm{A} 2, \mathrm{~B} 1, \mathrm{C} 4$ & $\mathrm{C} 2$ & $\mathrm{~A} 1, \mathrm{C} 3$ & $\mathrm{~A} 3, \mathrm{~B} 2, \mathrm{~B} 3, \mathrm{C} 1$ & \\
\hline Dutifulness & B1 & $\mathrm{B} 2, \mathrm{C} 1, \mathrm{C} 4$ & $\mathrm{~A} 1, \mathrm{~A} 2, \mathrm{~A} 3, \mathrm{C} 2, \mathrm{C} 3$ & & B3 \\
\hline Achievement striving & & & $\mathrm{A} 1, \mathrm{~A} 2, \mathrm{~A} 3, \mathrm{~B} 1, \mathrm{~B} 2, \mathrm{~B} 3, \mathrm{C} 1, \mathrm{C} 3, \mathrm{C} 4$ & $\mathrm{C} 2$ & \\
\hline Self discipline & $\mathrm{B} 1$ & $\mathrm{C} 1, \mathrm{C} 3, \mathrm{C} 4$ & $\mathrm{~A} 2, \mathrm{~A} 3, \mathrm{~B} 2, \mathrm{C} 2$ & $\mathrm{~A} 1, \mathrm{~B} 3$ & \\
\hline Deliberation & $\mathrm{B} 2, \mathrm{C} 2$ & $\mathrm{~A} 3, \mathrm{C} 3$ & $\mathrm{~A} 1, \mathrm{~A} 2, \mathrm{~B} 1, \mathrm{C} 1, \mathrm{C} 4$ & B3 & \\
\hline
\end{tabular}

Table 2. The 10 group members' test result on factors and facets according to the personality scoring scheme running from 'very low' (-34) to 'very high' (66-). Factors are highlighted in bold. 
When looking at the T-scores on factors in table 2 it is interesting to see that many of the group members scored 'high' on neuroticism. According to the test instrument this indicates that the participants - except for B3 - might be sensitive to stress and uncertainty.

With relevance to group work all group members scored 'medium' to 'high' on extraversion - one of the social factors. Further, most of the group members scored 'high' - and in two occasions even 'very high' - on openness to experience, which considers intellectual aspects. According to the test instrument this indicates a positive attitude towards changes, an intellectual curiosity and willingness to think in alternative and unconventional ways. Except for B1, B3, C4, group members were generally scoring 'medium' on conscientiousness, which may indicate a tendency towards an efficient and trustworthy approach to the work task.

To sum up, the similarities across groups and group members concerning the general personality traits were primarily reflected in high levels of neuroticism, middle to high levels of extraversion, high levels of openness to experience and middle levels of conscientiousness. Based on the test result and previous work on personality and information behaviour (Heinström, 2002) some hypotheses about group members' information behaviour were formulated. It was expected that most of the group members would demonstrate a tendency towards high affective levels of uncertainty and stress during the project assignment process. Further, it was expected that they would try to reduce stress, uncertainty, and complexity by employing rational information strategies or 'principles of least effort' ${ }^{\prime 11}$ such as using known information sources (Kuhlthau, Heinström \& Todd, 2008) or limiting the recall of information. At the same time, however, these hypotheses were expected to interfere with group members' 'openness to experience', hence their expected preferences for new as well as a broad range of information. Moreover, the middle to high score on extraversion was expected to reflect a collaborative orientation towards information behaviour.

\section{Affective Experiences and the Work Task Process}

Though most of the group members turned out to be persons with high levels of neuroticism, they generally demonstrated low affective values of uncertainty and medium to high values of confidence during the work task process, even at the beginning, in contrast to Kuhlthau's (1991; 2004) ISP-model. This is further demonstrated in figures 3-5, which show group members' experiences of confidence, clarity and uncertainty during the assignment process.

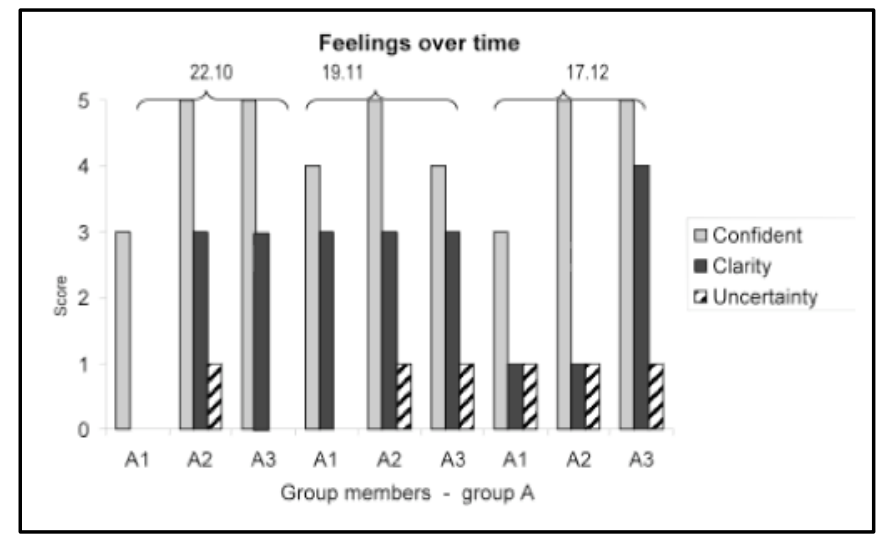

\footnotetext{
${ }^{11}$ Principle of 'least effort' is a theory of user behaviour held among researchers in the field of library and information science. The principle states that an information seeking client will tend to use the most convenient search method, in the least exacting mode available. Information seeking behaviour stops as soon as minimally acceptable results are found (Wikipedia: http://en.wikipedia.org/wiki/Principle_of_least_effort.)
} 
Figure 3. Perceived experiences of confidence, clarity and uncertainty for the three group A members as expressed by a number from 1 (low) to 5 (high) in the three process surveys: at the 22 th of October, the 19 th of November and the $17^{\text {th }}$ of December.

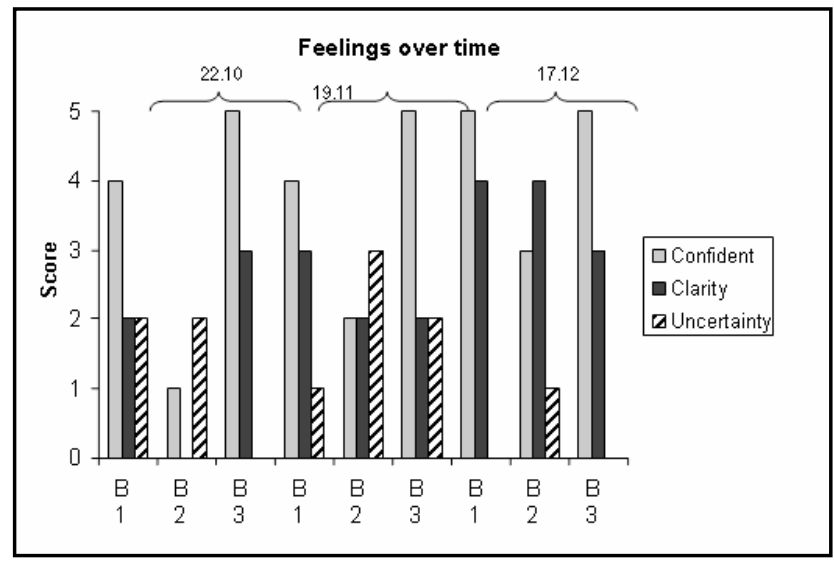

Figure 4. Perceived experiences of confidence, clarity and uncertainty for the three group B members as expressed by a number from 1 (low) to 5 (high) in the three process surveys: at the 22 th of October, the $19^{\text {th }}$ of November and the $17^{\text {th }}$ of December.

During the interviews it turned out that the affective experiences of uncertainty and confidence generally were associated positively with 'social and professional familiarity' with other group members, e.g. ones preceding knowledge of other group members' ambitions, working style and attitude towards the work task process. The same affective pattern of uncertainty and confidence was also demonstrated during the three diary-periods at start, midpoint and end.

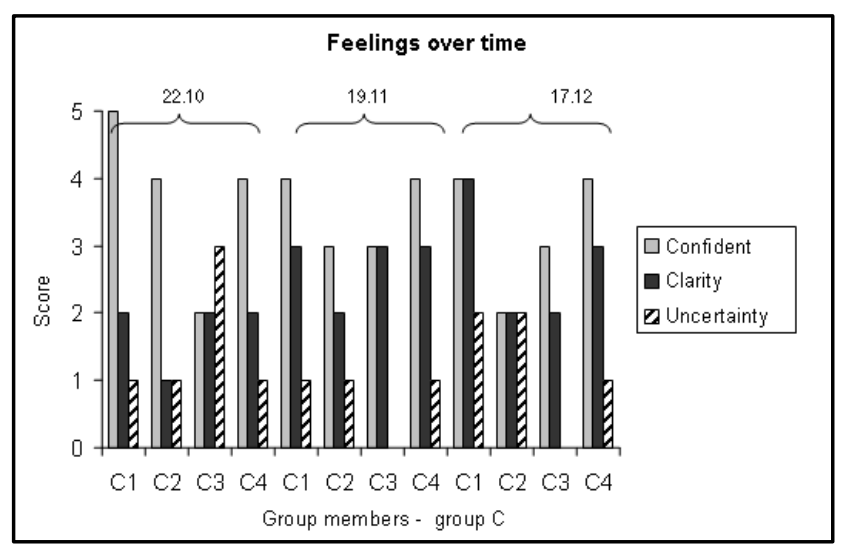

Figure 5. Perceived experiences of confidence, clarity and uncertainty for the three group $\mathbf{C}$ members as expressed by a number from 1 (low) to 5 (high) in the three process surveys: at the 22 th of October, the $19^{\text {th }}$ of November and the $17^{\text {th }}$ of December.

With regard to clarity, which is the feeling associated with focus formulation, only 'low' to 'medium' values were generally experienced during the project assignment process according to the process surveys in figures 3-5. This result may indicate that group members had not been clear about the focus of the assignment at the time of reporting, not even at the last time of reporting, two weeks before deadline. The medium degree of clarity at start in group A turned out to be associated more with confidence and trust in the group's professional and social 
performance than with the assignment itself. The same affective pattern of clarity was also reflected in the diaries. Based on these findings no strong relation between experiences of clarity and manifestations of uncertainty could be identified. With regard to frustration, only none to medium $(=3)$ levels of frustration in relation to the work task were identified in the process surveys and diaries across groups. However, group members with high levels of neuroticism, particularly regarding the facets pessimism, nervousness and social fear, more often experienced feelings of frustration, either due to group work issues or the progress of the work task process. With regard to 'stress' - another manifestation of uncertainty - no general pattern could be identified across groups when looking at the average values of stress (see table $3)$.

\begin{tabular}{|l|c|c|c|}
\hline \multicolumn{5}{|c|}{ Stress } \\
\hline Group & 1. diary & 2. diary & 3. diary \\
\hline A & 7 & 5 & 9 \\
\hline B & 13 & 15 & 3 \\
\hline C & 8 & 14 & 13 \\
\hline
\end{tabular}

Table 3. Group perception of 'stress' during time. Average values on a scale from 0-5 for each diary period (7 days) and for each group (max=7x5=35) (Hyldegård, 2009, p. 151).

An interesting finding in this context was that the mere act of writing actually helped reduce stress as mentioned by many group members. In turn, it could also easily provoke stress if no writing activity had taken place for a while, both at the individual and at the group level. This also seemed to be influensed by personality factors, as the most uncertain group members, such as B2 with regard to the facets associated with 'neuroticism', in general also showed higher values of stress across the process than the more secure group members.

When looking at the differences in affective values among group members they may as well be explained by personal factors, but may also be explained by the organisation of the work task process. Whereas activities were performed collaboratively at the pre- and post-focus stage, activities were often performed individually at the focus-formulation stages, when parts of the assignment were distributed to individual group members. Further, a deadline at midpoint on another project assignment also resulted in a more fragmented group work at that stage, thus, in more individual activities and different affective experiences.

\section{Affective Experiences and the Group Work Process}

As demonstrated in figures 2-5, high levels of 'confidence' were generally experienced across group members in addition to generally 'low' values of 'uncertainty' during the assignment process. It was mentioned briefly in the previous sub-section, but it turned out that this affective behaviour was associated with group member familiarity. The groups had, for example, been formed out of familiarity rather than out of interests in the assignment topic. In the interviews it was mentioned that familiarity with other group members often made them feel more safe, relaxed and confident with regard to the work task. In addition, implications of feeling safe, respected and accepted in the group provided a basis for giving constructive feedback, asking 'silly' questions or come up with new ideas and suggestions. Furthermore, when you feel safe in a group, uncertainty and lack of confidence tended to decrease, as some group members mentioned. Familiarity also meant that no time had to be spend on getting to know the other group members and - in some cases - that they knew what role to take in the group. The importance of sharing the same ambitions, working principles and working style was also 
stressed. Moreover, being satisfied with the process and the product seemed to affect the individual's perception of confidence and certainty as well. Social factors may, however, also affect negatively. This was, for example, seen in group $\mathrm{C}$ at midpoint due to a personal conflict between group member $\mathrm{C} 1$ and $\mathrm{C} 2$. For these group members the conflict resulted in a slight decrease in motivation, interest and clarification, and an increase in uncertainty and stress.

\section{Affective Experiences and the Information Seeking Process}

Affective experiences among group members associated with uncertainty were also identified during the information seeking process and in relation to the information searching situation, in particular. This is shown in table 4.

\begin{tabular}{|c|c|c|c|c|c|c|c|c|c|c|c|c|}
\hline \multirow{2}{*}{$\begin{array}{l}\text { FEELINGS } \\
\text { TIME }\end{array}$} & \multicolumn{3}{|l|}{ Difficult } & \multicolumn{3}{|l|}{ Stress } & \multicolumn{3}{|c|}{ Complex } & \multicolumn{3}{|c|}{ Frustrating } \\
\hline & start & mid-point & end & start & mid-point & end & start & mid-point & end & start & mid-point & end \\
\hline A1 & 3 & 2 & 4 & 3 & 2 & 3 & 4 & 3 & 4 & 2 & 2 & 3 \\
\hline A2 & 2 & 4 & 3 & 3 & 4 & 2 & 4 & 2 & 3 & 3 & 2 & 3 \\
\hline A3 & 1 & 4 & 1 & 1 & 3 & 1 & 1 & 4 & 1 & 3 & 3 & 1 \\
\hline Average & 2 & 3 & 3 & 2 & 3 & 2 & 3 & 3 & 3 & 3 & 2 & 2 \\
\hline B1 & 3 & 2 & 3 & 4 & 2 & 3 & 4 & 3 & 3 & 3 & 4 & 3 \\
\hline B2 & 4 & 3 & 2 & 3 & 4 & 2 & 4 & 3 & 2 & 4 & 3 & 2 \\
\hline B3 & 1 & 2 & 3 & 2 & 1 & 3 & 3 & 3 & 3 & 1 & 3 & 3 \\
\hline Average & 3 & 2 & 3 & 3 & 2 & 3 & 4 & 3 & 3 & 3 & 3 & 3 \\
\hline C1 & 2 & 2 & 2 & 2 & 3 & 3 & 3 & 3 & 3 & 2 & 3 & 3 \\
\hline $\mathrm{C2}$ & 2 & 0 & 4 & 1 & 0 & 3 & 2 & 0 & 4 & 1 & 0 & 3 \\
\hline C3 & 3 & 3 & 2 & 3 & 2 & 3 & 5 & 3 & 1 & 4 & 4 & 1 \\
\hline C4 & 3 & 3 & 3 & 3 & 3 & 3 & 4 & 3 & 3 & 3 & 3 & 2 \\
\hline Average & 3 & 3 & 3 & 2 & 3 & 3 & 4 & 3 & 3 & 3 & 3 & 2 \\
\hline
\end{tabular}

Table 4. Group members' affective experiences in association with 'information searching'. The table is based on group member values assigned to affective dichotomies on a scale from 1 (positive) to 5 (negative) in each of the three process surveys at start, midpoint and end. C2 was not seeking information at midpoint, hence the ' 0 '-values (Hyldegård, 2009, p. 153).

As demonstrated in the table many of the group members perceived information searching as 'complex' (value 4-5), particularly at the prefocus-stage where no focus had been found yet. But also at midpoint and towards the end of the assignment process 'some' complexity was found in addition to 'some' 'difficulty', 'stress' and 'frustration'. This may also indicate that information searching only rarely was considered 'easy', 'relaxing', 'simple' and 'satisfying' by groups. In contrast to the affective experiences associated with the work task process more negative feelings were identified in relation to information seeking activities. In line with the ISP-model it could be explained by the specific stage of the problem solving process, hence, group members' present knowledge of the work task topic. It also seemed to be associated with their own perceived level of their search task knowledge and skills. This could again change negatively or positively when compared to the performance of other group members. Some group members also had difficulties in judging relevance of retrieved information, but this was often found to be associated with the complexity of the delegated part of the assignment.

When looking at group members' approach to information seeking the hypotheses derived from the personality test regarding 'openness to experience' and 'conscientiousness' often matched group members' actual information behaviour. Interesingly, no manifestations of information seeking strategies towards low recall (information avoidance) or complexity reduction were observed as a matter of group members' high scores on 'neuroticism'. 
In group $A$, each group member searched information on her own at the begining, but informed the others of relevant information and by sending links. At group meetings search terms were exchanged, both at start and at midpoint, and the relevance of information sources searched or read - was discussed. Later, when parts of the assignment had been delegated in the group, information was exchanged or distributed to specific group members if considered relevant.

Most of the searching in group $B$ was performed in common by sitting in the same room, but with each group member at her computer searching different information sources for practical reasons. During this process, the relevance of information was discussed and search expressions and keywords were exchanged. At meetings, in particular at start and midpoint, information was also shared and exchanged. When, information sources had been read by one group member a summary followed by a relevance assessment was often given to the other group members.

In group $C$, group members generally searched much of their information on a collaboratively basis at the beginning, either by sitting at the same computer or by dividing the search between them, implying specific but different information sources (channels) to be searched. Relevant search terms and information was shared and exchanged during meetings. After midpoint and towards the end, searching was performed more individually, partly for practical reasons as the final focus was reached very late in the process, but also due to the delegation of specific parts of the assignment. Information was, however, still exchanged among group members if considered relevant. According to C3, being four group members in the group had resulted in more aspects, but also in more time spent on discussing the relevance of information sources. This was partly caused by a difference in relevance criteria.

\section{Discussion}

Based on the results presented above this section discusses the 'uncertainty dimension' of group members' information behaviour by comparing group members' behaviour with the individual information seeker in the ISP-model (research question 1) and by looking at the influence from personal, work task and social factors (research question 2).

When addressing the cognitive dimension of uncertainty underlying Kuhlthau's ISPmodel it was surprising that only low levels of uncertainty in addition to medium to high levels of confidence were identified at start and during the assignment process. This is further motivated by the fact that only low to medium levels of 'clarity' (focus formulation) generally were experienced by group members during the process and that most of the group members had high levels of 'neuroticism'. One explanation may be found within social psychology. According to Fiske (2004) people often tend to depersonalize when they identify with a group, which implies that they become less oriented to their individual identity, while orienting more towards being a prototypic member of the group. Assimilating 'self' to the group's prescriptive prototype generally reduces feelings of uncertainty by providing guides for thoughts, feelings and actions. Another explanation, which this study also seemed to support, may be the identified importance of familiarity with other group members. Familiarity was found to have a strong influence on group members' affective experiences since it was connected positively with ones preceding knowledge of other group members' ambitions, working style, ethics and attitude towards the work task process. With reference to the group development process (Tuckman,1965), the three groups almost 'jumped' into the norming stage from the right beginning. These groups also had many elements in common with Limberg's (1998) 'holistic' approach to group work, e.g. demonstrated by a strong 'we-mode'-orientation in the groups and a collaborative approach to information behaviour. The importance of social and professional familiarity in group work was also identified by Hyldegård (2006a) in a case study of two groups of 5 LIS students. Her study showed that the group where the group members knew each 
other in advance managed to formulate a shared focus and experienced only low levels of uncertainty. In contrast, the group in which group members were new to each other had many difficulties in finding a shared focus and often perceived negative feelings of uncertainty, stress, frustration and disappointment, even at the end in contrast to the ISP-model. The latter group ended up entering the presentation stage of the ISP-model without a clear focus and did not seem to reach the last and 'performing' stage of the group process. With regard to information seeking information was generally searched on an individual basis and without any negotiated information seeking strategy. It was strategically exchanged and shared, primarily at the prefocus-stage. Effective discussions and sharing of information were only limited, which constrained the goal of finding a shared focus. This group had many elements in common with Limberg's (1998) 'atomistic' approach to group work, e.g. by demonstrating a strong 'I-mode'orientation among group members and a lack in perception of the 'whole'. The importance of familiarity and experiences of uncertainty in group work may not only be associated with cognitive and social factors, but may as well be related to personality factors. Since most of the group members had high levels of neuroticism and the primary reason for group formation turned out to be 'familiarity with other group members', a positive relation might also exist between personality traits and preferences for group work, which suppresses negative personality effects accordingly. According to Costa \& McCrae (1992), some facets of high neuroticism may also enhance certain types of critical thinking, as 'neuroticism' also can be a measure of being irritable and defensive. Hence, neuroticism may not in all cases be associated negatively with nervousness and anxiety. The open and conscientious characteristics of the group members due to the personality test may also have contributed positively to the affective experiences during the assignment process. Following from this, the idea of familiarity tends to play an important role, hence should not be ignored in studies of as well as approaches to collaborative information behaviour within academic settings. The importance of familiarity may however, not only apply to groups in an academic context, but to teams in a professional context as well.

Whereas social factors seemed to influence positively on the group members' experiences of uncertainty during the assignment process, lack of clarity (knowledge gap) may have influenced negatively on group members' experiences of the information searching process - in line with the ISP-model (Kuhlthau, 2004). More negative feelings and manifestations of uncertainty, such as complexity, stress, difficulty and frustration, were here identified during the assignment process, particularly at start. In contrast to the ISP-model, however, the negative feelings were not replaced by positive feelings towards the end of the assignment process. According to Kuhlthau (1991; 2004), this may imply that no focus had actually been found. However, if we acknowledge the impact from the context, group members' affective behaviour may also have been influenced by the very search situation, e.g. as a result of poor information competencies among group members or a poor search interface. Regarding the work task dimension of uncertainty a pause in writing due to another assignment implied a negative progress of the assignment process, resulting in feelings of stress. In addition, the deadline of the assignment could provoke experiences of stress. Though stress generally was negative to the individual group member it seemed, however, to have a positive impact on the very group process by provoking action. Experiences of uncertainty and anxiety associated with the library context (Onwuebuzie,1997) or the end product (Cheuk Wai-Yi, 1998) were not identified in this study.

\section{Limitations}

Some methodological limitations of this study which may have affected the validity of the results should be mentioned. The complexity of the uncertainty concept represents a weakness regarding the research design. In order to control the different dimensions of uncertainty affective data have been collected to enable a differentiation between uncertainty and the work task, the information seeking process and group work. But this is in fact an artificial distinction; 
in nature the feeling of uncertainty rather interacts dynamically between these different factors of influence. In addition, some of the participants stated that it was somewhat odd to express a feeling by a number; the number was an indicator of each group member's perceived affective experiences at the time of reporting. With regard to the personality test it was based on selfreporting, meaning that the test results may have been influenced by how the group member perceived her- or himself or wanted to be perceived.

\section{Conclusion}

This study has explored the uncertainty dimension of group based problem solving and the associated information behaviour in groups. This behaviour has been compared to the individual information seeker in Kuhlthau's ISP-model. In addition, social as well as personal and contextual factors have been taken into account. Based on the data from a qualitative and longitudinal case study approach it was found that group members' experiences of uncertainty did not correspond to the ISP model. Low levels of uncertainty and high levels of confidence were identified in the beginning of the assignment process. This may indicate that other factors beyond the information searching process intermingle with the complex process of knowledge construction and meaning making.

Concerning the personal factor all of the group members had high levels of 'neuroticism' due to which high levels of uncertainty were expected. Some of the group members with 'very high' levels of neuroticism did demonstrate experiences of uncertainty, frustration and stress that tended to derive from personality traits, but this was only rarely reflected in their affective experiences of the work task process in general. Uncertainty was found to be associated with the social factor of personal and professional 'familiarity with other group members', which turned out to have a positive influence on group members' experiences of uncertainty and confidence, and on the group work process itself. With regard to the work task factor perceived feelings of stress were identified in relation to information searching, but also in relation to the progress of the assignment and the approaching of the deadline.

The results from this study have further highlighted the complexity of the uncertainty dimension of information behaviour in an academic and complex problem solving setting. As the study has shown, perceptions of uncertainty may not only differ according to the stage of the knowledge construction process (the uncertainty principle), but also according to social aspects, personal traits, the information search task and the work task situation. It can be concluded that the uncertainty concept is a muliti-dimensional phenomenon, which should not be studied out of context.

When serving information seekers, information providers, mediators (digital or physical) and supervisors should be aware of the different expressions and manifestations of uncertainty that may interfere with the knowledge construction process.

The groups in the present study experienced low levels of uncertainty due to personal and professional familiarity. This is not always the case - neither in academic settings nor in the professional sector where people often work in teams out of their professional background and experience rather than familiarity. In these cases the role of the mediator is important to help group members build a shared knowledge base that will contribute to their obtaining of a shared focus and help them keep an eye on the collective product and goal. While keeping Kuhlthau's 'zones of intervention' in mind it should be relevant to explore more systematically how group members themselves could act as formal mediators, who assist, guide, enable and intervene in other group members' information seeking process to help reduce or overcome negative effects of uncertainty on group performance. In addition to that the relation between experiences of uncertainty, group performance and learning outcome should be further explored. 


\section{Acknowledgement}

I would like to thank Niels Ole Pors at the Royal School of Library and Information Science and the reviewers at NORIL for thought provoking and supportive comments and suggestions during the writing of this article.

\section{References}

Anderson, T. D. (2006). Uncertainty in action: observing information seeking within the creative processes of scholarly research. Information Research, 12(1) paper 283. Retrieved 17.3.2009, from http://InformationR.net/ir/12-1/paper283.html

Belkin, N.J.; Oddy, R.N. \& Brooks, H.M. (1982). ASK for information retrieval. Part I: Background and theory. Journal of Documentation, 38(2): 61-71.

Berger, C.R. \& Calabrese, R. (1975). Some explorations in initial interactions and beyond: Toward a developmental theory of interpersonal communication. Human Communication Research, 1, 99-112.

Brewer, M.B. \& Harasty, A.S. (1996). Seeing groups as entities: the role of the perceiver motivation. In R. M. Sorentino \& E.T. Higgins (Eds.), Handbook of motivation and cognition: the interpersonal context (pp. 347-370). New York: Guilford Press.

Bruce, H.; Fidel, R.; Pejtersen, A.M.; Dumais, S. \& Grudin, J. (2003). A comparison of the collaborative information retrieval of two design teams. The New Review of Information Behavior Research, 4, 139-153.

Byström, K. (1999). Task complexity, information types and information sources: Examination of relationships. (Doctoral Dissertation, University of Tampare, Finland, 1999). Retrieved 17.3.2009, from http://www.hb.se/bhs/personal/katriina/kby-diss.pdf

Byström, K. \& Hansen, P. (2005).Conceptual framework for tasks in information studies. Journal of the American Society for Information science and Technology, 56(10): 1050-1061.

Byström, K. \& Järvelin, K. (1995). Task complexity affects information seeking and use. Information Processing and Management, 31(2), 191-213.

Case, D. (2007). Looking for information: A survey of research on information seeking, needs, and behavior. New York: Academic Press/Elsevier Science.

Castano, E.; Yzerbyt, V.; Paladino, M. \& Sacchi, S. (2002). I belong therefore I exist: Ingroup identification, ingroup entitativity, and ingroup bias. $P S P B, 28(2), 135-143$.

Cheuk Wai-Yi, B. (1998). An information seeking and using process model in the workplace: a constructivist approach. Asian Libraries, 7(12), 375-390.

Costa, P.T \& McCrae, R.R. (1997). Stability and change in personality assessment: the revised NEO Personality Inventory in the year 2000. Journal of Personality assessment, 68(1), 8694.

Costa, P.T \& McCrae, R.R. (1992). NEO PI-R. Professional manual. Odessa: Psychological Assessment Resources, Inc.

Dervin, B. (1983). An overview of Sense-Making research: Concepts, methods and results to date. Paper presented at the Annual Meeting of the International Association, Dallas, TX. 
Fidel, R., Bruce, H., Pejtersen, A.M., Dumais, S., Grudin, J., \& Poltrock, S. (2000). Collaborative information retrieval (CIR). New Review of Information Behaviour Research: Studies of Information Seeking in Context: vol. 1(1), 235-247.

Fiske, S. T. (2004). Social beings. Core motives in social psychology. Princeton, New Jersey: Wiley.

Heinström, J. (2002). Fast surfers, broad scanners and deep divers - personality and information seeking behaviour. Åbo: Åbo Akademi University Press.

Huber, G.L., Sorrentino, R.M., Davidson, M.A., Epplier, R. \& Roth, J.W.H. (1992). Uncertatinty orientation and cooperative learning: individual differences within and across cultures. Learning and Individual Differences, 4, 1-24.

Humphreys, M. S. \& Revelle, W. (1984). Personality, motivation and performance. A theory of the relationship between individual differences and information processing. Psychological Review, 91(2), 153-184.

Hyldegård, J. (2009). Beyond the search process - Exploring group members' information behavior in context. Information Processing \& Management, 45, 142-158. Retrieved 15.3.2009 from http://dx.doi.org/10.1016/j.ipm.2008.05.007

Hyldegård, J. (2006a). Collaborative information seeking - exploring Kuhlthau's Information Search Process-model in a group-based educational setting. Information Processing and Management, 42(1), 276-298.

Hyldegård, J. (2006b). Between individual and group - exploring group members' information behaviour in context. Kbh. Unpublished doctoral dissertation, Royal School of Library and Information Science, Copenhagen, Denmark.

Ingwersen, P. \& Järvelin, K. (2005). The turn: Integration of information seeking and retrieval in context. Dordrecht: Springer.

Kracker, J. (2002). Research anxiety and students' perceptions of research: An experiment. Part I. Effect of teaching Kuhlthaus's ISP model. Journal of the American Society for Information Science and Technology, 53(4), 282-294.

Kracker, J. \& Wang, P. (2002). Research anxiety and students' perceptions of research: an experiment. Part II. Content analysis of their writings on two experiences. Journal of the American Society for Information Science and Technology, 53(4), 295-307.

Kuhlthau, C.C. (2004). Seeking meaning - a process approach to library and information services. London: Libraries Unlimited.

Kuhlthau, C.C. (1991). Inside the Search Process: Seeking meaning from the users perspective. Journal of the American Society for Information Science, 42(5), 361-371.

Kuhlthau, C.C., Heinström, J. \& Todd, R.J. (2008). "The 'information search process' revisited: is the model still useful?" Information Research, 13(4) paper 355. [Available at http://InformationR.net/ir/13-4/paper355.html]

Limberg, L. (1998). Att söka information för att lära - et studie av samspel mellan informationssökning och lärende. Borås: Publiceringsföreningen Valfried. (Avhandling vid institutionen för biblioteks- och informationsvetenskap vid Göteborgs Universitet).

Nahl, D. (2007). The centrality of the affective in information behavior. In D. Nahl \& D. Bilal (Eds.), Information and emotion: The emergent affective paradigm in information behavior research and theory. (pp. 3-37). Medford, New Jersey: Information Today. 
Onwuegbuzie, A. (1997). Writing a research proposal: the role of library anxiety, statistics anxiety and composition anxiety. Library and Information Science research, 19(1), 5-33.

Prekop, P. (2002). A qualitative study of collaborative information seeking. Journal of Documentation, 58(5), 533-547.

Reddy, M.C. \& Jansen, B.J. (2008). A model for understanding collaborative information behavior in context: a study of two healthcare teams. Information Processing \& Management, 44, 256-273.

Shannon, C. E. \& Weaver, W. (1964). The Mathematical Theory of Communication. Urbane: University of Illinois Press.

Sonnenwald, D. \& Pierce, L.G. (2000). Information behavior in dynamic group work contexts: interwoven situational awareness, dense social networks and contested collaboration in command and control. Information Processing and Management, 36, 461-479.

Sorrrentino, R.M., Hodson, G. \& Huber, G.L. (2001). Uncertainty orientation and the social mind: Individual differences in the interpersonal context. In J.P. Forgas, K.D. Williams \& L. Wheeler. (Eds.), The social mind - cognitive and motivational aspects of interpersonal behavior. (pp. 199-227) Cambridge: Cambridge University press.

Sorrentino, R.M. \& Roney, C.J.R. (2000). The uncertain mind: Individual differences in facing the unknown. Lillington, NC: Edwards Brothers.

Strauss, A. \& Corbin, J. (1998). Basics of qualitative research - techniques and procedures for developing grounded theory. 2nd. edition. London: Sage Publications.

Tuckman, B. W. (1965). Developmental sequence in small groups. Psychological Bulletin, 63, 384399.

Tuomela, R. \& Tuomela, M. (2005). Cooperation and trust in group context. Mind \& Society, 4, 4984.

Vakkari, P. (2001). A theory of the task-based information retrieval process: a summary and generalization of a longitudinal study. Journal of Documentation, 57(1), 44-60.

Wilson, T. D. (1999). Models in information behaviour research. Journal of Documentation, 55(3), 249-270. 